\title{
Transport Kinetics of Alpha-Aminoisobutyric Acid and Water in Pre-Eclamptic Pregnancies: An in vitro Study
}

\author{
Moorkath Nandakumaran ${ }^{a}$ Alexander Omu ${ }^{a}$ Michael Diejomaoha \\ Majda Al-Yatama Assem K. Harouny ${ }^{b}$ Thattaruparambil N. Sugathanc \\ Departments of a Obstetrics and Gynaecology and ${ }^{b}$ Community Medicine, Faculty of Medicine, Kuwait University, \\ cHadi Clinic, Kuwait
}

\section{Key Words}

Alpha-aminoisobutyric acid · In vitro study · Placental perfusion . Pre-eclamptic pregnancies . Tritiated water

\begin{abstract}
Objective: To investigate the transport kinetics of a model amino acid, alpha-aminoisobutyric acid (AIB), in the maternal-fetal direction in placentae from pre-eclamptic pregnancies. Methods: Transport kinetics of the amino acid was assessed in vitro using perfusion of human placental lobules. Control placental lobules were perfused for comparison. National Culture and Tissue Collection135 medium diluted with Earle's buffered salt solution was used as the perfusate, and tritiated water served as the internal reference marker. AIB along with reference marker was injected as a single bolus into the maternal arterial perfusate, and serial perfusate samples were collected from maternal and fetal venous circuits for a study period of $5 \mathrm{~min}$. Results: The differential transport rate of the amino acid for various efflux fractions differed significantly between control and experimental groups when compared to that of the reference marker. The transport rate (corresponding to $50 \%$ of efflux into the fetal vein), transport fraction, absorption and elimination rates of the amino acid differed significantly compared to the ref-
\end{abstract}

erence marker values in study and control groups. Conclusion: The results indicate that amino acid transport function is compromised in placentae of pre-eclamptic pregnancies.

Copyright $@ 2002$ S. Karger AG, Basel

\section{Introduction}

Pre-eclampsia-eclampsia syndrome (PEES) and pregnancy-induced hypertension are both well recognized as contributing to perinatal and maternal morbidity and mortality. It is also well established that pre-eclampsia has a potential restraining effect on fetal growth, with intrauterine growth retardation being associated with severe, protracted forms of PEES [1-3]. Despite being a wellknown complication of pregnancy, reports on the maternal-fetal exchange of nutrients or other substances in this disease condition are scanty. Based on a study of placental clearance of sodium, Browne and Veall [4] reported a compromised membrane transport function in preeclamptic pregnancies. However, Cockburn et al. [5] were unable to detect such compromise using maternal-fetal amino acid gradients to compare the transport function in placentae from pre-eclamptic women with that of normotensive women. Absence of a suitable animal model mim-

\section{KARGER \\ Fax + 41613061234 \\ E-Mail karger@karger.ch \\ www. karger.com}

Dr. M. Nandakumaran

Associate Professor, Obstetrics and Gynecology Department

Faculty of Medicine, Kuwait University

PO Box 24923, Safat 13110 (Kuwait)

Tel. +965 5319601, Fax +965 5338906, E-Mail moorkath@hsc.kuniv.edu.kw 
icking the pre-eclamptic situation has also been responsible for the scarcity of valuable data on maternal-fetal exchange in PEES states. Development of an in vitro perfusion system of placental lobules has permitted us to investigate the role of the placental membrane in maternal-fetal transport of a variety of nutrients and drugs in both control as well as disease states [6-8]. To our knowledge, no study has specifically investigated transport behaviour or transport kinetics of major nutrients in the non-steady state in PEES pregnancies. Hence, we chose to investigate the transport kinetics of a model amino acid, alpha-aminoisobutyric acid (AIB), in placentae from PEES pregnancies and to compare the data with those obtained from control, uncomplicated pregnancies. AIB was chosen for the study because it is non-metabolizable and is well known to represent the type A transporter system in the placental tissue [9]. Also, this amino acid has been used extensively for investigating placental permeation by several groups [10-12]. Tritiated water served as the reference marker in the control and study series.

\section{Materials and Methods}

\section{Placentae}

Placentae were collected immediately after delivery. Fetal as well as maternal circulations of suitable placental lobules were then cannulated and perfused using National Culture and Tissue Collection medium (Sigma Chemical Co., USA) diluted with buffered Earle's salt solution as perfusate $[7,8]$. The sodium concentration of the perfusate mixture was maintained in the physiological range, averaging $140 \mathrm{mmol} / \mathrm{l}$ in both the experimental and control perfusion series. Placentae from pre-eclamptic women were obtained from patients clinically diagnosed as suffering from PEES (table 1). All pre-eclampsia patients received appropriate anti-hypertensive therapy until delivery. Control placentae were obtained from women who had had a normal, uncomplicated pregnancy with a normal blood pressure record for the duration of their pregnancy. The placentae in both the groups came from caesarean sections. The placentae from control women matched those in the study group for gestational age at the time of delivery.

\section{Perfusion Method}

Perfusion of isolated placental lobules was performed as described previously [6-8]. After an initial wash-out phase of $10 \mathrm{~min}$, $1 \mu \mathrm{Ci}$ of tritiated water (Amersham; specific activity $5 \mathrm{mCi} / \mathrm{mmol}$ ) and $0.5 \mu \mathrm{Ci}$ of ${ }^{14} \mathrm{C}$-labelled $\mathrm{AIB}$ (Amersham; specific activity $3.9 \mathrm{mCi} / \mathrm{mmol}$ ) were injected as a $100-\mu \mathrm{l}$ bolus into the maternal arterial circulation at a site close to the insertion of microcannulas in the basal plate, and serial samples were collected from the maternal and fetal circuits for a period of $5 \mathrm{~min}$, after a lag period of $1 \mathrm{~min}$. The lag period of $1 \mathrm{~min}$ before sample collection was based on the findings of our previous study [13]. The study period of $5 \mathrm{~min}$ was based on the time required for $90 \%$ of injected radioactivity in the bolus to appear in the combined fetal and maternal venous efflux in control sham perfusions [9]. Perfusion flow rates in both the circuits were measured by BROOKS R 215 flow meters, while perfusion pressures were monitored by mercury manometers.

The viability of perfusions was assessed by determining the oxygen consumption of the perfused tissue during the period of study [14] and by verifying the absence of perfusion flow rate mismatch between fetal arterial inflow and fetal venous outflow rates. Radioactivity in perfusate samples and injected boluses was determined by liquid scintillation counting (LKB Wallac Model, Copenhagen, Denmark), using pre-adjusted windows and external standardization. Necessary corrections were made to minimize isotope crossover and isotope quenching of coloured samples.

\section{Transport Parameters}

Maternal-fetal transport of AIB and tritiated water was expressed as the differential transport rate, i.e. the time in minutes for a given fraction to be transported across to the fetal vein $[13,15]$ :

efflux fractions $=$

${ }^{3} \mathrm{H}$ or ${ }^{14} \mathrm{C}$ dpm in the fetal venous sample total ${ }^{3} \mathrm{H}$ or ${ }^{14} \mathrm{C} \mathrm{dpm}$ in fetal vein for the period of $5 \mathrm{~min}$

From the curve obtained by plotting various cumulative efflux fractions as a function of perfusion time, the time in minutes for efflux of 10, 25, 50, 75 and $90 \%$ of total venous efflux was then computed. Control studies had established that these efflux times for

Table 1. Characteristics of pre-eclampsia patients

\begin{tabular}{llllllll}
\hline $\begin{array}{l}\text { Patient } \\
\text { No. }\end{array}$ & $\begin{array}{l}\text { Maternal } \\
\text { age } \\
\text { years }\end{array}$ & Parity & $\begin{array}{l}\text { Gestational } \\
\text { age } \\
\text { weeks }\end{array}$ & $\begin{array}{l}\text { BP before } \\
\text { caesarean } \\
\text { section, mm Hg }\end{array}$ & $\begin{array}{l}\text { Weight of } \\
\text { newborn } \\
\text { g }\end{array}$ & $\begin{array}{l}\text { Placental } \\
\text { weight } \\
\mathrm{g}\end{array}$ & $\begin{array}{l}\text { Albumin } \\
\text { in urine }\end{array}$ \\
\hline P1 & 36 & $3+0$ & 39 & $160 / 90$ & 2,800 & 600 & ++ \\
P2 & 35 & $5+0$ & 38 & $150 / 110$ & 3,100 & 500 & ++ \\
P3 & 26 & $1+0$ & 38 & $170 / 110$ & 2,750 & 500 & +++ \\
P4 & 24 & $0+0$ & 36 & $140 / 100$ & 2,400 & 350 & ++ \\
P5 & 29 & $2+0$ & 37 & $150 / 110$ & 2,700 & 550 & ++ \\
\hline
\end{tabular}

Blood pressure (BP) is expressed as systolic/diastolic values. Albuminuria was assessed by the Esbach test. 
study substances varied little with increasing or decreasing doses, for a given set of fetal-maternal flow rates.

Transport rate indices of AIB for the various efflux fractions were computed by expressing the values of the amino acid as a ratio of corresponding reference marker values. Expression of amino acid transport rates as an index of the reference marker helps the researcher to take into account factors such as minor variations in flow rates, perfusion pressures, differences in membrane surface area of perfused lobules and shunts, among others, and permits ready comparison of data between experiments.

The transport fraction (TF) of the substances studied was calculated thus $[15,16]$ :

$\mathrm{TF}=$

total ${ }^{3} \mathrm{H}$ or ${ }^{14} \mathrm{C} \mathrm{dpm}$ in fetal venous efflux for period of $5 \mathrm{~min}$ total ${ }^{3} \mathrm{H}$ or ${ }^{14} \mathrm{C} \mathrm{dpm}$ in the injected bolus

Calculation of the ratio or index relating the TF of the test substance studied to that of the reference substance permitted assessment of the TF of the amino acid, independent of minor variations in factors such as flow rate, shunts and changes in membrane surface area, as outlined above.

The area under the curve (AUC) of the substances studied was determined by the trapezoid rule, assuming a two-compartment model and using the following formula $[13,17,18]$ :

$$
\mathrm{AUC}=\sum_{\mathrm{i}=1}^{\mathrm{n}} \frac{[\mathrm{C}(\mathrm{i}+1)+\mathrm{C}(\mathrm{i})] \times[\mathrm{t}(\mathrm{i}+1)-\mathrm{t}(\mathrm{i})]}{2}+\frac{\mathrm{C}(\mathrm{n})}{\mathrm{K}_{\mathrm{el}}},
$$

where $\mathrm{C}$ is the concentration of the substance in the sample, $\mathrm{t}$ is the time in seconds of sample collection, $\mathrm{n}$ is the number of experimental points, $\mathrm{C}(\mathrm{n})$ is the last experimental point or measurement and $\mathrm{K}_{\mathrm{el}}$ is the elimination constant.

Other kinetic parameters such as clearance, $\mathrm{K}_{\mathrm{el}}$, time for maximal response (Tmax), absorption and elimination rates were determined using a computer program based on IMSL FORTRAN SUBROUTINE software, especially adapted for statistical applications. The software was run on a VAX/VMS 6510 computer.

To assess the nature of AIB transport, another transport parameter was also employed. TF indices of AIB in fetal perfusate venous samples were plotted cumulatively as a function of perfusion time in control and pre-eclampsia groups and the rate of permeation across the placental membrane was determined [8].

\section{Statistical Analysis}

All data are given as mean \pm SEM. Statistical analysis was done by ANOVA and paired or unpaired Student's t test, where appropriate (Graphpad Instat Program using Graphpad software V2-05+). Analysis of co-variance was used to assess the significance of transport rate slopes of the amino acid between study and control perfusions. A probability level of $\mathrm{p}<0.05$ was considered statistically significant.

\section{Results}

Table 1 summarizes the characteristics of 5 PEES patients from whom placentae were obtained at the time of delivery. The maternal age, weights of the newborns and placenta and gestational age of the 5 control women averaged $30.3 \pm 3.8$ years, $3,032 \pm 276.2 \mathrm{~g}, 586 \pm 22.3 \mathrm{~g}$ and $38.2 \pm 1.06$ weeks, respectively. The above parameters did not differ significantly (Student's unpaired t test, $p>$ 0.05 ) between the study and control groups. All the women in the control group had normal systolic and diastolic blood pressure values within the physiological range and had a normal, uncomplicated course of pregnancy.

In the control series, the fetal perfusion flow rate averaged $3.8 \pm 0.2 \mathrm{ml} / \mathrm{min}$ in 5 perfusions, while in the preeclampsia series $(n=5)$, it averaged $4.0 \pm 0.2 \mathrm{ml} / \mathrm{min}$. The maternal perfusate flow rate in the control and preeclampsia series averaged $11.2 \pm 0.3$ and $10.9 \pm 0.4 \mathrm{ml} /$ min, respectively. Perfusion pressure in the maternal and fetal circuit averaged $54.2 \pm 6.2$ and $32 \pm 2.4 \mathrm{~mm} \mathrm{Hg}$, respectively, in the control series. In the study series, maternal and fetal perfusion pressures averaged $56.6 \pm$ 4.8 and $34.3 \pm 2.8 \mathrm{~mm} \mathrm{Hg}$, respectively. Cotyledon weights averaged $46.1 \pm 3.2 \mathrm{~g}$ in the control series, while in the pre-eclampsia group, cotyledon weights averaged $42.3 \pm 4.5 \mathrm{~g}$.

Differential transport rates of tritiated water for 10,25, 50,75 and $90 \%$ of efflux fractions in fetal veins averaged $0.93 \pm 0.11,1.52 \pm 0.12,1.97 \pm 0.12,2.80 \pm 0.13$ and $3.56 \pm 0.14 \mathrm{~min}$ in 5 pre-eclamptic placentae, while in control perfusions $(n=5)$, the values for the corresponding efflux fractions averaged $0.77 \pm 0.06,1.40 \pm 0.09$, $1.66 \pm 0.21,2.70 \pm 0.18$ and $3.50 \pm 0.16 \mathrm{~min}$, respectively. Analysis of means by Student's t test did not show any significant difference $(\mathrm{p}>0.05)$ between corresponding water transport rates in the control and study groups. Paired Student's t test showed that tritiated water and AIB differential transport rates differed significantly $(\mathrm{p}<$ 0.05 ) for all the efflux fractions studied, both in control as well as pre-eclamptic perfusions.

Differential transport rate indices of AIB in preeclamptic and control placentae compared to those of the reference marker are shown in table 2. ANOVA showed that the values were significantly higher $(p<0.05)$ in the pre-eclamptic series than in controls for all efflux fractions studied, implying a delayed amino acid transport in the diseased condition. Differential transport rate values of tritiated water did not differ significantly (ANOVA, $p>$ 0.05 ) between the control and study series. Further, fetal and maternal perfusate flow rates and perfusion pressures were not significantly different (unpaired Student's t test, $\mathrm{p}>0.05$ ) between the two groups. Oxygen consumption of the perfused lobules averaged $0.18 \pm 0.06$ and $0.16 \pm$ $0.07 \mu \mathrm{mol} / \mathrm{min} / \mathrm{g}$ in control and pre-eclampsia groups, respectively. Unpaired Student's t test showed no statisti- 
Table 2. AIB differential transport rate indices in pre-eclamptic and control placentae

\begin{tabular}{llllll}
\hline \multicolumn{5}{l}{ AIB differential transport rate } \\
& \multicolumn{4}{l}{ Water differential transport rate (mean \pm SEM) } \\
\cline { 2 - 6 } & TR 10** & TR 25** & TR 50** & TR 75*** & TR 90** \\
\hline Control & $0.77 \pm 0.03$ & $0.80 \pm 0.02$ & $0.96 \pm 0.03$ & $0.98 \pm 0.02$ & $0.96 \pm 0.04$ \\
Pre-eclampsia & $1.21 \pm 0.01$ & $1.24 \pm 0.09$ & $1.24 \pm 0.03$ & $1.15 \pm 0.03$ & $1.11 \pm 0.02$ \\
\hline
\end{tabular}

Results are expressed as means of 5 successful perfusions in each series.

$\mathrm{TR}=$ Differential transport rate at various times in minutes. ${ }^{* *} \mathrm{p}<0.01 ; * * * \mathrm{p}<0.001$.

Table 3. Transport kinetics of tritiated water in pre-eclampsia and control perfusion series

\begin{tabular}{llllllll}
\hline & $\begin{array}{l}\text { AUC } \\
\text { dis/h/g }\end{array}$ & $\begin{array}{l}\text { Clearance } \\
\mathrm{ml} / \mathrm{min}\end{array}$ & $\mathrm{K}_{\mathrm{el}}$ & \multicolumn{2}{l}{$\begin{array}{l}\text { Tmax } \\
\mathrm{s}\end{array}$} & $\begin{array}{l}\text { Absorption } \\
\text { rate, dpm }\end{array}$ & $\begin{array}{l}\text { Elimination } \\
\text { rate, dpm }\end{array}$ \\
\hline $\begin{array}{l}\text { Control } \\
\text { Pre-eclampsia }\end{array}$ & $912,340 \pm 483,454$ & $23.8 \pm 18.7$ & $49 \pm 25.4$ & $138.8 \pm 10.7$ & $1,090 \pm 265.7$ & $\begin{array}{l}2,009 \pm 1,026.8 \\
\end{array}$ \\
\hline
\end{tabular}

Values represent means of 5 successful perfusions in each series. Dis $=$ Disintegrations.

$p>0.05$ for all measurements.

Table 4. AIB kinetic indices in pre-eclamptic and control placentae

\begin{tabular}{lllllll}
\hline & $\begin{array}{l}\text { AUC } \\
\text { index** }\end{array}$ & $\begin{array}{l}\text { Clearance } \\
\text { index* }\end{array}$ & $\begin{array}{l}\mathrm{K}_{\mathrm{el}} \\
\text { index }\end{array}$ & $\begin{array}{l}\text { Tmax } \\
\text { index** }\end{array}$ & $\begin{array}{l}\text { Absorption } \\
\text { rate index*** }\end{array}$ & $\begin{array}{l}\text { Elimination } \\
\text { rate index*** }\end{array}$ \\
\hline $\begin{array}{l}\text { Control } \\
\text { Pre-eclampsia }\end{array}$ & $0.28 \pm 0.03$ & $8.24 \pm 0.61$ & $0.42 \pm 0.06$ & $1.01 \pm 0.02$ & $0.24 \pm 0.02$ & $0.16 \pm 0.01$ \\
& $0.102 \pm 0.03$ & $10.31 \pm 1.4$ & $0.27 \pm 0.05$ & $1.19 \pm 0.04$ & $0.08 \pm 0.00$ & $0.08 \pm 0.00$ \\
\hline
\end{tabular}

Values represent means of 5 successful perfusions in each series. Kinetic indices show AIB value $/ \mathrm{H}_{2} \mathrm{O}$ value.

$* \mathrm{p}>0.05$ (not significant), ${ }^{* *} \mathrm{p}<0.01 ; * * * \mathrm{p}<0.001$.

cal significance between these values in the control and study series.

Transport kinetic parameters such as AUC, clearance, $\mathrm{K}_{\mathrm{el}}$, Tmax, absorption rate and elimination rate of tritiated water in pre-eclamptic and control perfusions are summarized in table 3. Analysis by ANOVA as well as unpaired Student's $t$ test showed no significant difference $(p>0.05)$ between the various transport parameters of tritiated water in the control and experimental groups. AIB transport kinetic parameters, expressed as a ratio or index of reference marker values in pre-eclamptic and control placentae, are shown in table 4. The AUC index of the amino acid compared to the reference marker was significantly lower and the Tmax index significantly higher in the pre-eclampsia group compared to corresponding indices in control perfusions (unpaired Student's t test, $\mathrm{p}>$ 0.05). Similarly, absorption rate and elimination rate indices of the amino acid were shown to be significantly lower (unpaired Student's t test, $p<0.05$ ) in the study group compared to the control values. However, no statistical difference could be shown (unpaired Student's t test, $\mathrm{p}>0.05$ ) between clearance and $\mathrm{K}_{\mathrm{el}}$ indices in the two groups.

The AIB transport rate corresponding to $50 \%$ of efflux (TR50) index in control experiments averaged $0.96 \pm$ 0.03 , while in the pre-eclampsia group, the index averaged $1.24 \pm 0.03$ (fig. 1). Unpaired Student's t test showed that the difference between the control and study groups was 
Fig. 1. Ratios of AIB TR 50 to $\mathrm{H}_{2} \mathrm{O}$ TR 50 in pre-eclampsia and control experiments. Results are means \pm SEM of 5 successful perfusions in each series. ${ }^{*} \mathrm{p}<0.05$.

Fig. 2. $\mathrm{AIB} T \mathrm{TF} / \mathrm{H}_{2} \mathrm{O}$ TF values in preeclampsia and control experiments. Results are means \pm SEM of 5 successful perfusions in each series. ${ }^{*} \mathrm{p}<0.05$.

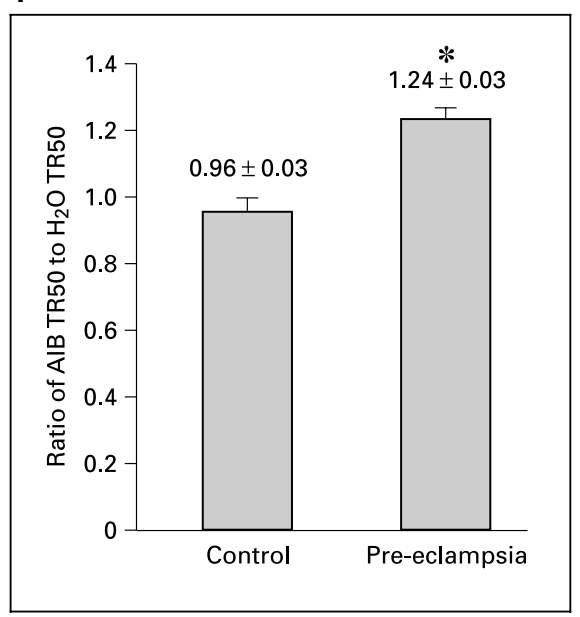

2

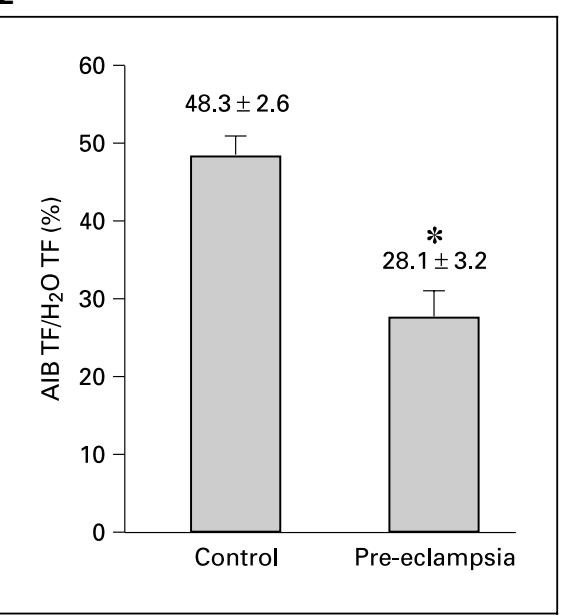

significant $(\mathrm{p}<0.05)$. The AIB TF averaged 28.1. $\pm 3.2 \%$ of the tritiated water TF in the pre-eclampsia series, while in control perfusions, the TF of the amino acid averaged $48.3 \pm 2.6 \%$ of the reference marker TF (fig. 2). Student's $t$ test revealed a significant difference between AIB TF indices $(p<0.05)$ in control and study groups. In accordance with the above findings, when AIB TFs were expressed as a percentage of injected bolus (fig. 3) and plotted as a function of perfusion time in the pre-eclampsia and control groups, the transport slope of the amino acid was significantly lower (analysis of co-variance, $\mathrm{p}<$ 0.05 ) in the former than in the latter.

\section{Discussion}

To our knowledge, the present report is the first to detail the transport kinetics of a model amino acid and tritiated water in pre-eclamptic pregnancies. The data on tritiated water and AIB kinetics in control pregnancies are comparable to those reported by us in earlier studies [ $[15$, 16]. No significant difference was observed in the case of water transport in control and PEES pregnancies, presumably because of the free permeability of the marker across biological membranes.

In the case of AIB, the transport kinetic data in control placentae are comparable to those reported by us earlier in normal uncomplicated pregnancies [16] and are in accordance with the active transport of the amino acid across the placental membrane, amply demonstrated by several other research groups $[10,11,19]$. The lower AIB transport observed in pre-eclamptic pregnancies may be attributed to the thickened basal membrane and other

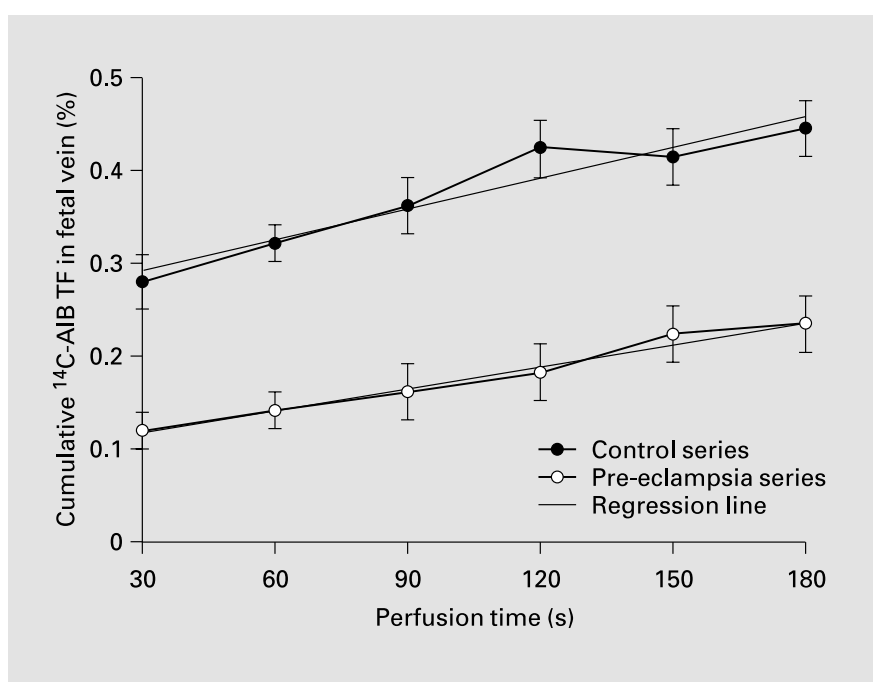

Fig. 3. Cumulative TFs of AIB in fetal venous outflow as a function of perfusion time. Each experimental point represents the mean \pm SEM of 5 successful perfusions in each series. The regression line for the pre-eclamptic perfusion series was drawn using the coefficients $b[0]$ 0.094; $b[1] 7.714257143 \mathrm{e}-4\left(\mathrm{r}^{2}=0.981451\right)$, while that for the control perfusion series was drawn using the coefficients $b[0]$ $0.258666 ; b[1] 1.076190 \mathrm{e}-3\left(r^{2}=0.926744\right)$. Statistical significance between the slopes was determined using analysis of co-variance $(\mathrm{p}<$ $0.05)$.

vascular and villous abnormalities reported in this condition [20-22]. Interestingly, a study conducted by our research group has demonstrated alteration of the $\mathrm{Na}^{+}-\mathrm{H}^{+}$ exchanger mechanism in pre-eclamptic placentae [23], and the present results of altered AIB transport kinetics seem to imply that the $\mathrm{Na}^{+}-\mathrm{H}^{+}$exchanger plays an impor- 
tant role in the transport of A-type amino acids. Lunell et al. [24] also reported that in pregnancies with compromised utero-placental blood flow, low fetal birth weight was not uniformly present in all such cases. Since amino acids constitute only a fraction of the total body energy needs, calculation of birth weight per se may not be a good indicator of the status of maternal-fetal neutral amino acid exchange. Further, considering the fact that the calculation of birth weight in itself may not reflect the status of fetal deprivation of amino acids, no attempt was made in this study to correlate the body weight of newborns with AIB transport kinetics data.

Generally, the results obtained in in vitro conditions cannot be extrapolated directly to in vivo pathological pre-eclamptic states. In the present investigation, fetal and maternal flow rates were maintained in the physiological range, but this ideal situation may not be present in pregnancies complicated by PEES. Several investigators have reported placental and villous abnormalities in preeclamptic pregnancies (such as thickened basement membrane and fibrin deposits) [20, 22]. Abnormalities such as increased vascular resistance $[25,26]$, augmented vascular reactivity to angiotensin II and noradrenaline [27, 28] and decreased plasma volume [29] have also been reported. A reduction of utero-placental blood flow of about 50-70\%, attributed mainly to the above factors, has been reported in pre-eclamptic pregnancies compared to control pregnancies [24]. The villous and vascular abnormalities mentioned above and the resultant reduction in utero-placental blood flow in pre-eclamptic states may play a deleterious role in restricting the maternal supply of nutrients as well as oxygen. It is likely that the higher TR50 index of AIB compared to the reference marker observed in this study is the result of the vascular and villous deficiencies cited above. It may also imply a less effective amino acid transport. The possible influence of hypoxia on the alteration of arachidonic acid and prostaglandin metabolism, with a resultant thromboxane-prostacyclin imbalance also cannot be discounted, with impaired $\mathrm{Na}^{+}-\mathrm{H}^{+}$exchanger and membrane transport function, as reported above.

Since fetal and maternal perfusate flows were maintained within the physiological range, it is open to speculation whether the results would have been different if the maternal flow had been reduced to $50 \%$ of normal, to approximate the flow situation reported in severe forms of PEES in vivo. Unpublished results from our laboratory in a 'toxaemia placental model' with compromised maternal perfusate flow seem to indicate that while the transport of freely diffusing water is significantly affected in the simulated toxaemic model, the reduction in amino acid transport is much less than anticipated. This may indeed be one of the safety mechanisms at the level of the placenta, to ensure minimum availability of amino acids in times of distress, as in compromised blood flow states caused by PEES or gestational diabetes mellitus. Such a phenomenon of increased placental transport efficiency upon restriction of placental size has been observed in the case of 3-O-methyl glucose in flow-restricted experimental sheep [30]. Currently, studies are in progress in our laboratory to evaluate the effect of flow rate changes on maternal-fetal transport of nutrient analogues in normal as well as pre-eclamptic pregnancies.

\section{Conclusion}

This in vitro study indicates that amino acid transport function may be compromised in pre-eclamptic pregnancies. It is conceivable that in vivo, the possibility of reduced amino acid transport to the fetus and the resultant ill effects of reduced amino acid supply could affect the health of the fetus as well as the neonate.

\section{Acknowledgements}

The authors with to thank Mrs. Nirmala Narayanan and Mrs. Susan George for their excellent technical assistance. This work was supported by Kuwait University Research Grants MOOO9, MDO 128 and $\mathrm{MOO} 32$.
80

Med Principles Pract 2002;11:75-81
Nandakumaran/Omu/Diejomaoh

Al-Yatama/Harouny/Sugathan 


\section{References}

1 Dewhurst CJ: Pre-eclampsia, eclampsia, hypertension and chronic renal disease; in Dewhurst CJ (ed): Integrated Obstetrics and Gynaecology for Postgraduates, ed 2. London, Blackwell Scientific, 1976, pp 282-303.

2 Cunningham FG, Lindeheimer MD: Hypertension in pregnancy. N Engl J Med 1992;326: 927-932.

3 Omu AE, Al-Othman S, Al-Qattan F, Al-Falah FZ, Sharma P: A comparative study of obstetric outcome of patients with pregnancy induced hypertension: Economic considerations. Acta Obstet Gynecol Scand 1996;75:443-448.

4 Browne JC, Veall N: The maternal placental blood flow in normotensive and hypertensive women. J Obstet Gynaecol Br Emp 1953;60: 141-147.

5 Cockburn F, Blagden A, Michie EA, Forfar JO: The influence of pre-eclampsia and diabetes mellitus on plasma free amino acids in maternal, umbilical vein and infant blood. J Obstet Gynaecol Br Commonw 1974;78:215-223.

6 Nandakumaran M, Gardey CL, Challier JC, Richard MO, Panigel M, Olive G: Transfer of salbutamol in the human placenta in vitro. Dev Pharmacol Ther 1981;3:88-98.

7 Nandakumaran M, Makhseed M, Al-Rayyes S, Al-Yatama M, Devarajan L, Sugathan T: Kinetics of palmitic acid transport in insulindependent diabetic pregnancies: In vitro study. Pediatr Int 2000;42:296-301.

8 Nandakumaran M, Al-Rayyes S, Al-Yatama M, Sugathan TN: Effect of glucose load on the transport kinetics of palmitic acid in the human placenta: An in vitro study. Clin Exp Pharmacol Physiol 1999;26:669-673.

9 Enders RH, Judd RM, Donohue TM, Smith $\mathrm{CH}$ : Placental amino acid uptake. III. Transport system for neutral amino acids. Am J Physiol 1976;230:706-710.

10 Schneider H, Proegler M, Sodha R, Dancis J: Asymmetrical transfer of alpha-aminoisobutyric acid (AIB), leucine and lysine across the in vitro perfused human placenta. Placenta 1987; $8: 141-151$.
11 Contractor SF, Stannard PJ: The use of AIB transport to assess the suitability of a system of human placental perfusion for drug transfer studies. Placenta 1983;4:19-29.

12 Karl PI, Alpy KL, Fisher SE: Amino acid transport by the cultured human placental trophoblast: Effect of insulin on AIB transport. Am J Physiol 1992;262:C834-C839.

13 Nandakumaran M, Sugathan TN: Assessment of transport dynamics in the perfused human placental lobule: In vitro study. Med Principles Pract 1992-93;3:219-222.

14 Hauguel S, Desmaizieres V, Challier JC: Glucose uptake, utilization, and transfer by the human placenta as functions of maternal glucose concentration. Pediatr Res 1986;20:269273.

15 Nandakumaran M, Makhseed M, Devarajan LV: Transport of water and insulin in insulindependent diabetic pregnancies: In vitro study. Diabetes Res 1995;28:9-15.

16 Nandakumaran M, Makhseed M, Al-Rayyes S, Sugathan TN: Transport kinetics of alpha-aminoisobutyric acid in the perfused human placental lobule in vitro. Med Principles Pract 1998;7:264-270.

17 Rey E, Nandakumaran M, Richard MO, Loose JP, D'Athis P, Saint-Maurice C, Olive G: Pharmacokinetics of flunitrazepam after single rectal administration in children. Dev Pharmacol Ther 1984;7(suppl 1):206-212.

18 Wagner JG: Properties of the Michaelis-Menten equation and its integrated form which are useful in pharmacokinetics. J Pharmacokinet Biopharm 1973;1:103-121.

19 Krishna BR, King RG, Brennecke SP: Acetyl choline output and maternal-fetal alpha aminoisobutyric acid transfer in the perfused human placental lobule. Reprod Fertil Dev 1991; 3:459-465.

20 Aherne W, Dunnill MS: Morphometry of the human placenta. Br Med Bull 1966;22:5-8.
21 Costin N, Craciun C, Craciun V: Electorn microscopic modifications in placentas of gravids with pregnancy induced hypertension; in Munteanu I, Rippmann ET, Hrubaru N (eds): Maternal-Fetal Risk in Gestosis. Rome, CIC Edizioni Internazionali, 1996, pp 55-57.

22 Thomson D, Paterson WG, Smart GE, MacDonald MK, Robson JS: The renal lesions of toxaemia and abruptio placentae studied by light and electron microscopy. J Obstet Gynaecol Br Commonw 1972;79:311-320.

23 Khan I, Al-Yatama M, Nandakumaran M: Expression of the $\mathrm{Na}^{+}-\mathrm{H}^{+}$exchanger isoform-1 and cyclooxygenases in human placentas: Their implications in preeclampsia. Biochem Mol Biol Int 1999;47:715-722.

24 Lunell NO, Nylund LE, Lewander R, Sarby B: Uteroplacental blood flow in pre-eclampsia measurements with indium-113m and a computer-linked gamma camera. Clin Exp Hypertens B 1982;1:105-117.

25 Ginsburg J, Duncan SL: Peripheral blood flow in normal pregnancy. Cardiovasc Res 1967;1: 132-137.

26 Spetz S: Peripheral circulation in pregnancy complicated by toxaemia. Acta Obstet Gynaecol Scand 1965;44(suppl 2):243-257.

27 Gant NF, Daley GL, Chand S, Whalley PJ, MacDonald PC: A study of angiotensin II pressor response throughout primigravid pregnancy. J Clin Invest 1973;52:2682-2689.

28 Talledo OE: Renin-angiotensin system in normal and toxemic pregnancies. IV. Inactivation of angiotensin in toxemic pregnancy. Am J Obstet Gynecol 1968;101:254-256.

29 Gallery E, Hunyor S, Gyory AZ: Plasma volume contraction: A significant factor in both pregnancy-associated hypertension (preeclampsia) and chronic hypertension in pregnancy. Q J Med 1979;192:593-602.

30 Owens JA, Falconer J, Robinson JS: Restriction of placental size in sheep enhances efficiency of placental transfer of antipyrine, 3-0methyl-D-glucose but not of urea. J Dev Physiol 1987;9:457-464. 